\title{
A Case of Cavernous Hemangioma in the Parapharyngeal Space as a Neurogenic Tumor
}

\author{
Ji Eun Choi and Yang-Sun Cho \\ Department of Otorhinolaryngology-Head and Neck Surgery, Sungkyunkwan University School of Medicine, Samsung Medical Center, \\ Seoul, Korea
}

\section{신경인성 종양으로 오인된 부인두 공간에 발생한 해면상 혈관종 1 예}

\author{
최 지 은·조 양 선 \\ 성균관대학교 의과대학 삼성서울병원 이비인후-두경부외과학교실
}

\author{
Received April 4, 2012 \\ Revised June 11,2012 \\ Accepted June 21, 2012 \\ Address for correspondence \\ Yang-Sun Cho, MD \\ Department of Otorhinolaryngology- \\ Head and Neck Surgery, \\ Sungkyunkwan University School \\ of Medicine, Samsung Medical \\ Center, 50 Irwon-dong, \\ Gangnam-gu, Seoul 135-710, Korea \\ Tel $+82-2-3410-3578$ \\ Fax $+82-2-3410-3879$ \\ E-mail yscho@skku.edu
}

Hemangiomas are the most common benign neoplasms, which frequently involve the region of head and neck. However, cavernous hemangiomas are extremely rare in the parapharyngeal space and there has been only a few case reports regarding the disease found in this region. Recently, we experienced a 57-year-old female patient with cavernous hemangioma involving the infratemporal fossa and parapharyngeal space. This case was surgically managed using the infratemporal fossa approach type B. Preoperatively, it was difficult to differentiate the mass of cavernous hemangioma from a neurogenic tumor and this led to a massive bleeding during the operawtion. The preoperative decision-making process and the role of diagnostic imaging were discussed with literature reviews.

Korean J Otorhinolaryngol-Head Neck Surg 2012;55:521-6

Key Words Cavernous · Hemangioma $\cdot$ Parapharyngeal space.
서 론
하는 바이다.

혈관종은 선천성 두경부 양성종양의 가장 흔한 원인이며 병리조직학적으로 해면상, 모세상 및 혼합형으로 분류된다. 두경부 영역에서는 모세상 혈관종이 가장 흔하며 구순, 구강 점막, 이하선, 설부, 후두 순으로 발생한다.,2) 그러나 부인두 공 간 내 발생한 해면상 혈관종은 매우 드물며 외국에서 보고된 예가 드물게 있었고 국내에서는 Koh 등에 에해 보고된 사례 가 있다. ${ }^{3-5)}$

저자들은 최근 부인두 공간 내 발생한 해면상 혈관종 1 예를 경험하였으며 국내에서 보고된 예의 경우 하악골 절단을 통 하여 종물을 제거하였으나 본 증례에서는 $\mathrm{B}$ 형 측두하와 접 근법을 통하여 종물을 제거하였으며 수술 전에 신경인성 종 양과 감별이 어려워 수술 중 대량출혈을 경험하였기에 진단 에 필요한 방사선학적 검사를 중심으로 문헌고찰과 함께 보고

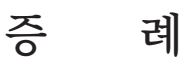

57세 여자 환자가 좌측 부인두 공간 내 종물을 주소로 내원 하였다. 환자는 약 2 년 전부터 이명과 청력 감소를 호소하여 외부병원에서 메니에르병 의증으로 이뇨제를 2년간 복용하였 으나 증상이 지속되고 두통이 있어 부비동 컴퓨터단층촬영 및 자기공명영상을 시행한 결과 좌측 부인두 공간 내 종물 이 발견 되어 전원되었다. 환자는 좌측 이명 및 청력 감소, 두통 을 호소하였으나 이통, 이루, 현훈, 안면마비 등의 소견은 보이 지 않았으며 과거력상 특이소견은 없었다.

외이도와 고막의 이경 검사에서 특이소견 없었으며 순음청 력검사(4분법, $500 \mathrm{~Hz}, 1000 \mathrm{~Hz}, 2000 \mathrm{~Hz}$ )상 좌측 기도청력 $50 \mathrm{~dB}$, 골도 청력 $50 \mathrm{~dB}$ 의 감각신경성 난청소견을 보였다(Fig. 1). 


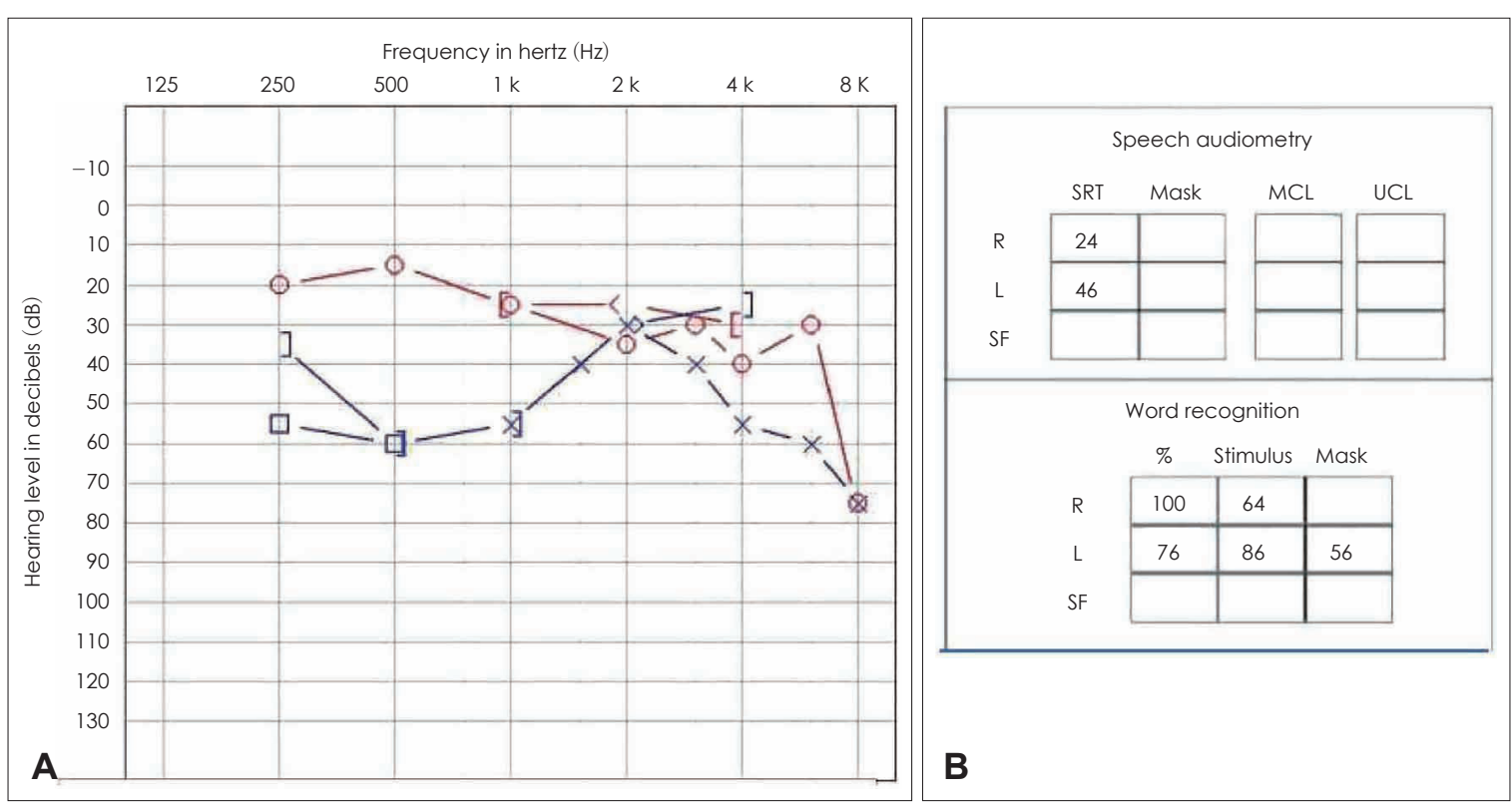

Fig. 1. Pure tone (A) and speech audiogram (B) of the patient. The audiogram shows left-sided sensory-neural hearing loss. SRT: speech recognition threshold, MCL: most comfortable level, UCL: level of loudness, SF: syllable frequency.

머리 자기공명영상상 좌측 측두와 및 부인두 공간에서 $\mathrm{T} 1$ 강조영상상 근육과 비슷한 신호강도를 가지는 $3 \mathrm{~cm}$ 가량의 종 물이 보였으며 난원공(foramen ovale)을 따라서 두개내로 확 장되고 있는 소견을 보였다. 종물은 균일한 조영 증강을 보이 며 T2 강조영상에서 전체적으로 고신호 강도를 보이고 있었 고 영상의학과 소견상 풍부한 혈관 분포를 가진 신경인성 종 양으로 색전술은 불필요하다고 하였다(Fig. 2).

신경인성 종양 진단 하에 전신마취로 측두하와 접근법 $\mathrm{B}$ 형 을 통하여 종양제거를 시도하였다. 고막과 이소골을 제거한 후 개방형 유양돌기절제술을 시행하였고 외이도 전방과 협골궁 의 후방을 노출하여 협골궁을 절단하였다. 수술 중 종양에 접 근할 때부터 조절이 어려운 출혈이 발생하기 시작하였고 종물 을 제거할 때에는 대량출혈이 있어서 수술 중 적혈구 8단위, 신선동결혈장 2 단위를 수혈하였으며 수술 후 혈소판 8 단위, 적혈구 3단위, 신선동결혈장 3단위를 추가로 수혈하였다.

협골궁 절단 후 측두하와를 노출하였고 난원공(foramen ovale)으로부터 기시한 하악신경의 주행을 확인하였다. 수술 소견상 종물은 하악신경과 붙어 있는 양상으로 분리되지 않아 하악신경을 종물과 함께 절단하였고(Fig. 3) 절단된 협골은 miniplate를 이용하여 재건하였다. 수술 중 시행한 동결절편 검사상 혈관성 종양이 의심되었으며, 추후 영구절편 및 면역 조직화학염색상 해면상 혈관종으로 진단되었다(Fig. 4).

환자는 좌측 하악신경 피부절(dermatome) 감각저하 소견 과 부정교합을 보였으나 이외 안면신경마비 등의 특이 합병증 없이 수술 후 9일째에 퇴원하였다. 수술 후 3개월 째 감각저하 는 호전되었으나 경미한 부정교합은 여전히 남아 있어 증상 지
속시 구강외과에서 턱관절 재건술을 고려해 보기로 하였다. 수술 후 시행한 컴퓨터단층촬영 및 자기공명영상상 재발의 징 후는 없으며(Fig. 5) 수술 후 1년째 추적관찰 중이다.

\section{고 찰}

혈관종은 영유아기의 양성종양을 대표하는 질환으로 대부 분 생후 1 세에 발병하여 2 세 이후에 서서히 퇴화하며 12 세 전 후에 자연 관해된다. ${ }^{1,7)}$ 따라서 성인에서의 혈관종은 소아에 비해 발생 빈도가 매우 낮으며 특히 부인두 공간 내에 발생 한 혈관종은 극히 드물어 2006년 Kale 등에에 의해 외국에서 보고된 바가 있으나 국내에서는 Koh 등이 이 1996년에 1예를 보고한 적이 있다.

혈관종 발생에 있어 여자에서 남자보다 약 2배 정도 빈번히 발생하며 임상적으로 환자가 느끼는 증상은 혈관종의 크기, 위치, 주위 구조물에 미치는 압력, 내부의 출혈이나 혈전 등과 관계 있는 것으로 알려져 있다.

조직학적으로 해면상 혈관종은 평활근이 결여된 얇은 섬유 성 벽을 가지고 있는 혈관이 확장된 소견이 보이면 진단할 수 있다. 혈관종은 한 개의 내피세포층으로 둘러싸여 있는 정상 또는 비정상적인 형태의 혈관 증식으로 구성되어 있으며 해면 상 혈관종은 주로 큰 정맥관이나 동양혈관(sinusoidal capillary)으로 구성된다.9) 혈관종은 주로 선천적으로 발생하며 아 직까지 발생기전과 원인은 명확히 규명되지는 않았지만 혈관 증식을 일으키는 인자나 표지자들이 증가된다고 알려져 있다. ${ }^{2)}$ Itoh 등이는 혈관종의 병변 범위의 확인에 있어 자기공명영 

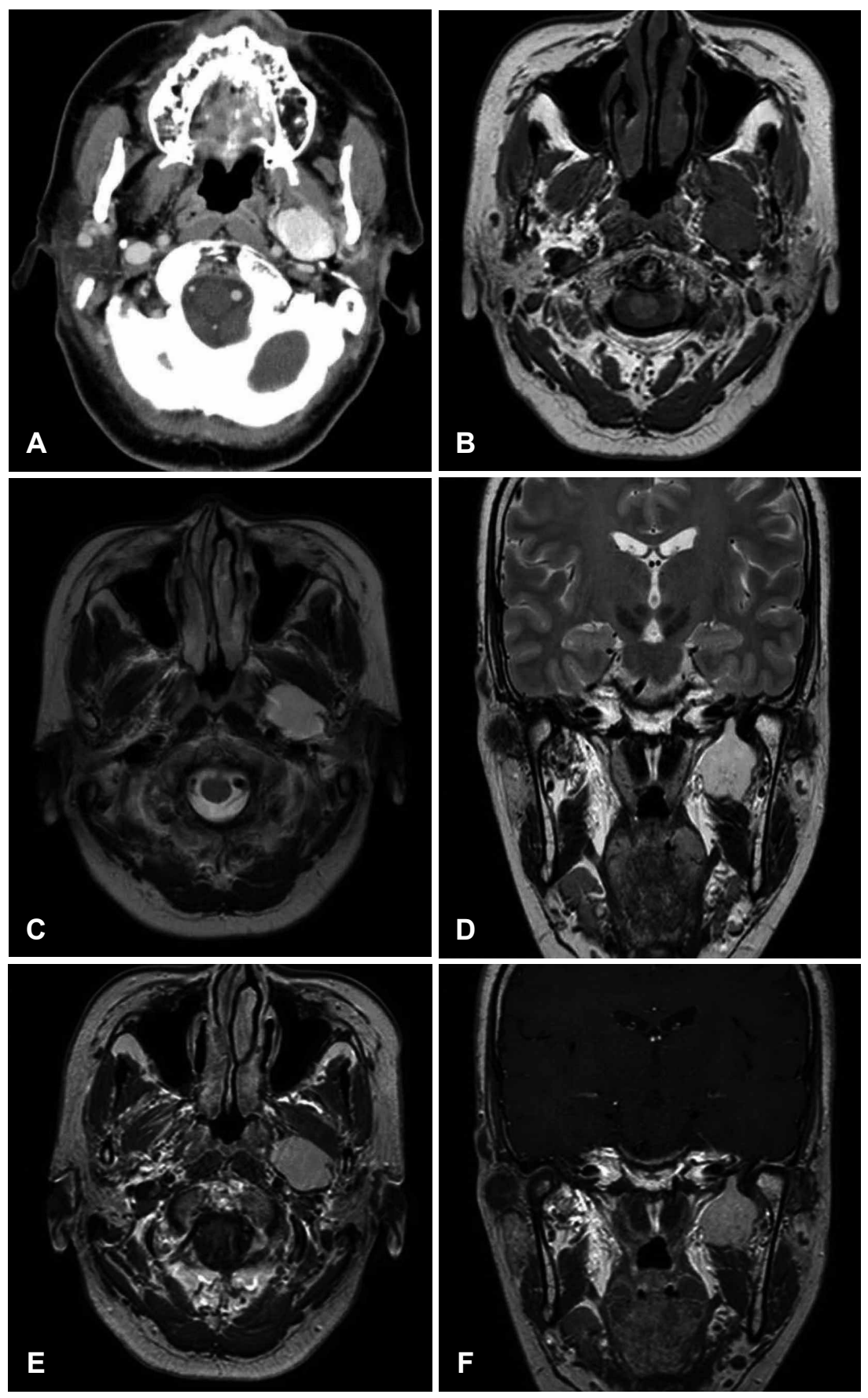

Fig. 2. Preoperative temporal bone axial CT scan (A) shows a contrast enhancing lesion in the left parapharyngeal space and infratemporal fossa. MR images show that the mass produces intermediate signal intensity on axial T1-weighted image (B) and homogenous, markedly high signal intensity on T2-weighted images ( $C$ and $D)$. The mass is strongly enhanced after contrast material administration, and extends into the foramen ovale ( $E$ and $F$ ).

상이 가장 좋은 영상진단검사이며 풍부한 혈액으로 인하여 $\mathrm{T} 2$ 강조영상에서 전체적으로 고신호 강도를 보이고 $\mathrm{T} 1$ 강조 영상에서는 근육과 비슷한 중등도 신호강도를 가진다고 보 고하였다. 측두골 컴퓨터단층촬영에서는 혈관성 종양을 시 사하는 낭성의 조영 증강 부위가 관찰되며 방사선 비투과성 의 정맥결석이 함께 관찰될 수 있으나 종양과 주변 정상조직 과의 구별이 어려우므로 자기공명영상이 컴퓨터단층촬영보 다 진단적 가치가 있다고 하였다. ${ }^{11)}$
혈관종의 치료는 추적 관찰로부터 수술까지 다양하며 성인 에서 발생한 경우 자연 관해가 드물기 때문에 적극적인 치료 가 권유된다. ${ }^{9)}$ 대부분의 혈관종은 점점 커지고 주위로 침투하 게 되므로 발견시에 수술을 하는 것이 원칙이며 수술 이외에 스테로이드 주입법, 냉동 요법, 주혈관 결찰술, 색전술, 레이저 응고법 등이 대안으로 제시되기도 하나 확실한 치료결과를 보 이지는 않는다. ${ }^{5)}$

수술을 시행할 때는 종물의 위치뿐만 아니라 크기, 병리학적 

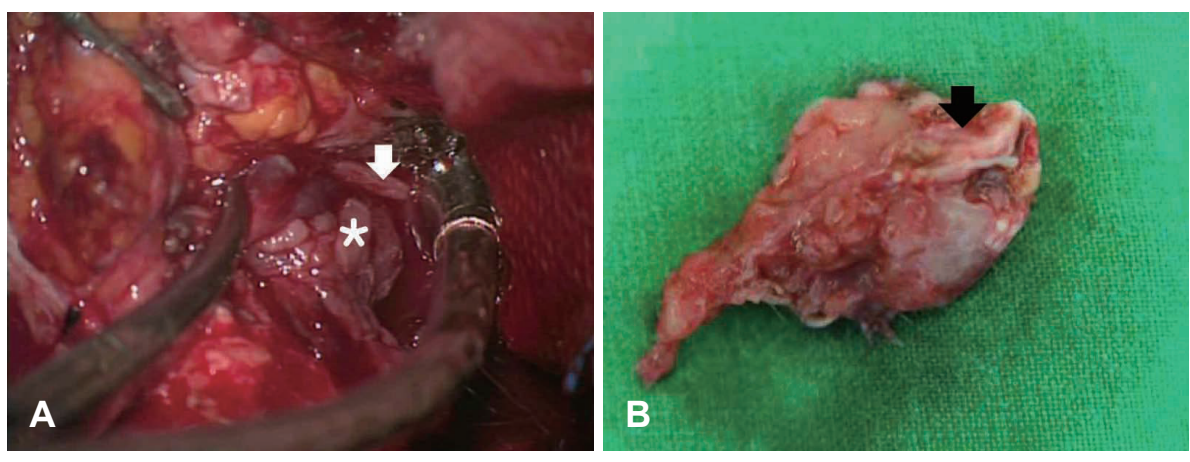

Fig. 3. Intraoperative finding showing that a $3 \mathrm{~cm}$ mass (asterisk) was attached to the mandibular branch of trigerminal nerve (white arrow) (A). The mass was removed with the nerve (black arrow)(B).
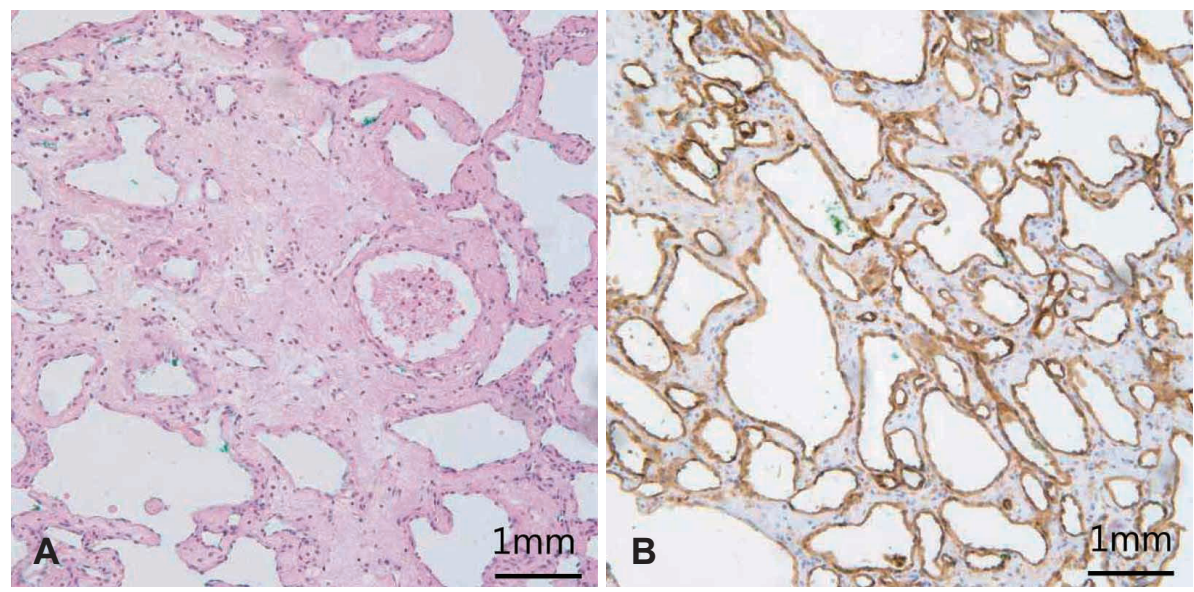

Fig. 4. The tumor is composed of large dilated blood-filled vessels with thin walls. The vessels are lined by flattened endothelium and surrounded with loose stoma (H\&E stain, $\times 200)($ A). The tumor was positive to the non-specific endothelial markers CD31 which confirms that it was a vascular origin tumor (B).
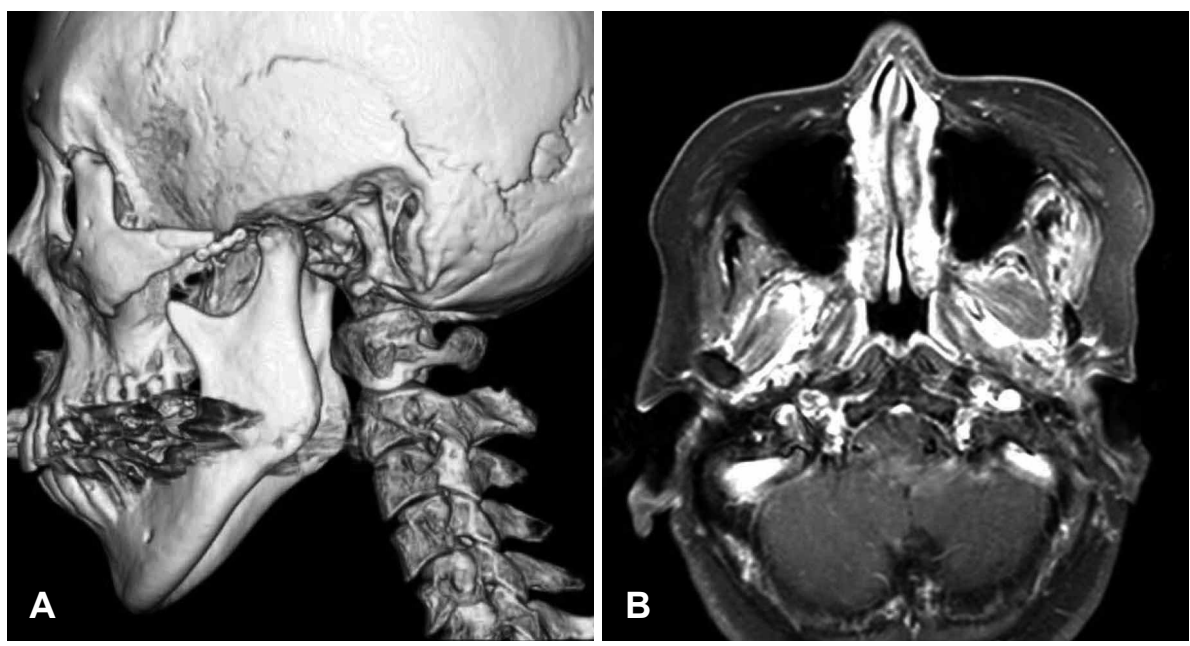

Fig. 5. Postoperative 3-dimenstional CT scan $(A)$ shows defects of the left glenoid fossa and mastoid process. Axial T1-weighted MR image with contrast shows no recurrent tumor (B).

소견이 중요하다. 술 전 검사상 양성 종물이 의심되는 경우라 도 혈관성 종물 또는 종양의 가능성을 배제하지 않아야 하며 대량 출혈을 대비하여 수술시야를 확보할 수 있어야 한다. 지 금까지 부인두 공간 내 종물 제거를 위해 보고된 접근법에는 1) 경구개 접근법, 2) 경부 접근법, 3) 경이하선 접근법(transparotid approach), 4) 하악골 회전법(mandibular swing), 5) 측두하와 접근법, 그리고 6) 중두개와 접근법을 포함한 두개 저 수술(skull base surgery)이 있다. ${ }^{12)}$ 경구개 접근법의 경우
크기가 작은 종물에 적합하며 수술 시야가 좁으므로 본 증례 에서는 적합하지 않았다. Kanzaki와 Nameki ${ }^{12)}$ 가 제시한 해 부학적 위치에 따른 수술적 접근법에 따르면 본 증례와 같이 부인두 공간 내 후상방에 위치하는 경우 두개저 수술, 하악 골 회전법 또는 측두하와 접근법이 적합하다고 하였다. 중두 개와 접근법을 이용한 두개저 수술은 대량출혈을 대비한 시 야 확보에는 적절하지 않은 방법이라고 생각되며, 하악골 회전 법의 경우 경하악골 접근법(transmandibular approach)의 하 
나로 절골술이 필요하여 부정유합, 수술 후 감염, 삼킴 장애, 얼굴 반흔을 유발할 수 있다. 측두하와 접근법은 청력손실이 생기며, 안면마비, 입벌림장애(trismus) 위험성이 있으나 본 증 례의 경우 수술 전 청력이 $50 \mathrm{~dB}$ 로 난청 소견(Fig. 1)을 보이고 있었으며 종물의 크기와 범위를 고려할 때 측두하와 B형 접 근법이 미용적, 기능적 측면에서 가장 이상적이라고 판단되 었다. ${ }^{12-14)}$ 측두하와 접근법에는 $\mathrm{Fisch}^{15)}$ 가 분류한 방법 이외 에도 다양한 수술방법이 제시되고 있으며 이 중 전이개 경협골 접근법(preauricular transzygomatic approach)도 본 증례 와 같은 부위에 접근하기에는 적합한 접근법으로 생각된다. 이 접근법은 측두하와의 전상방에 종양이 위치하는 경우 적합 하며 하악신경과 상악신경을 이동시킴으로써 수술 시야를 확 보할 수 있는 방법으로 수술 후 청력손실을 야기하는 측두 하와 접근법에 비해 청력을 보전할 수 있는 이점이 있다. 본 증 례의 경우 비교적 측두하와의 후방에 위치하며 수술 전 난청 이 있어 넓은 시야를 확보할 수 있는 측두하와 B형 접근법을 사용하였으나, 측두하와 종양의 위치나 크기에 따라 전이개 경협골 접근법을 고려할 수 있을 것이다. ${ }^{16)}$

수술시에는 혈관이 매우 발달되어 있으므로 출혈이 쉽게 발생되기 때문에 세밀한 박리가 반드시 필요한데 65 명의 해면 정맥동의 혈관종 환자를 대상으로 시행한 연구에서 수술 전 후 조절되지 않는 출혈로 사망한 경우도 $12.5 \%$ 정도로 보고 되고 있다. ${ }^{17)} \mathrm{Zhou}$ 등 ${ }^{18}$ 이 보고한 바에 따르면 38.9\%에서 수 술 전 해면상 혈관종을 진단하지 못하였듯이, 본 증례에서도 수술 중 예상하지 못했던 대량출혈을 경험하였으므로, 향후 방사선학적으로 진단이 명확하지 않을 때에는 혈관종이 가능 성을 고려한 정확한 술 전 평가가 필수적이라고 사료된다. 혈 관성분이 풍부한 신경성 종양의 경우에도 $\mathrm{T} 2$ 강조영상에서 강한 신호를 가지며 조영 증강이 될 수 있으므로 진단에 주의 해야 하며 역동적 조영 증강 자기공명영상이 감별에 도움을 줄 수 있다. ${ }^{17)}$ 혈관종의 경우 조영제 주입 초기에는 동맥혈의 낮은 혈류로 인하여 국한된 병변에서 조영 증강을 보이며 후 기 정맥기에 늘어난 혈관으로 점차 조영제가 충만되면서 안으 로 차 들어가며 균질한 조영 증강 양상을 보인다. 혈관주위세 포종(hemangiopericytomas)이나 혈관성분이 풍부한 신경인 성 종양의 경우 넓은 구역에서 조영 증강이 되며 빠르게 조영 씻김(wash-out) 양상이 나타나므로 감별진단에 도움을 줄 수 있다. ${ }^{19}$

혈관조영술의 경우 종물의 혈관 상태를 평가하여 진단에 도 움을 받을 수 있으며 술 전 영양 혈관(feeding vessel)이 조영 된다면 색전술을 통하여 혈류량을 감소시키고 수술 중 혈액 손실을 차단할 수 있다. 색전술 후에는 시간이 경과함에 따라 측부 혈행이 생길 수 있으므로 일반적으로 72시간 이내에 수
술을 시행하는 것이 좋다고 알려져 있다. ${ }^{5}$ 본 증례에서 알 수 있듯이 부인두 공간 내 혈관종은 매우 드물어서 감별진단에 서 제외될 가능성이 있으므로 이 위치에 조영 증강되는 병변 이 있거나 혈관성 종물이 의심되는 경우에는 역동적 조영 증 강 자기공명영상을 시행하여 술 전 진단을 명확히 하고 수술 중 출혈 가능성이 클 것으로 생각될 시 혈관조영술을 고려하 여 영양 혈관이 조영될 때 색전술을 시행할 수 있다. 8,20$)$

\section{REFERENCES}

1) Shpitzer T, Noyek AM, Witterick I, Kassel T, Ichise M, Gullane P, et al. Noncutaneous cavernous hemangiomas of the head and neck. Am J Otolaryngol 1997;18(6):367-74.

2) Song SY, Choi YH, Bai CH. Cavernous hemangioma of the external auditory canal: a case report. Korean J Otolaryngol-Head Neck Surg 2006; 49(8):845-8.

3) Gallina E, Ninu MB, Boccuzzi S, Rucci L. [Tumors of the lateral parapharyngeal space. Our case series]. Acta Otorhinolaryngol Ital 1991; 11(1):73-83.

4) Presutti L, Molteni G, Malvè L, Marchioni D, Ghidini A, Tassi S, et al. Parapharyngeal space tumors without mandibulotomy: our experience. Eur Arch Otorhinolaryngol 2012;269(1):265-73.

5) Capote A, Acero J, García-Recuero I, Rey J, Guerra B, de Paz V. Infratemporal-preauricular-cervical approach for resection of a cavernous intramasseteric hemangioma: a case report. J Oral Maxillofac Surg 2008; 66(11):2393-7.

6) Koh JW, Koo SM, Shin SJ, Joo HJ. A case of cavernous hemangioma involving the parapharyngeal space. Korean J Otolaryngol-Head Neck Surg 1996;39(5):887-91.

7) Kornfehl J, Gstöttner W, Kontrus M, Sedivy R. Transpalatine excision of a cavernous hemangioma of the infratemporal fossa. Eur Arch Otorhinolaryngol 1996;253(3):172-5.

8) Kale US, Ruckley RW, Edge CJ. Cavernous hemangioma of the parapharyngeal space. Indian J Otolaryngol Head Neck Surg 2006;58(1): 77-80.

9) McMenamin M, Quinn A, Barry H, Sleeman D, Wilson G, Toner M. Cavernous hemangioma in the submandibular gland masquerading as sialadenitis: case report. Oral Surg Oral Med Oral Pathol Oral Radiol Endod 1997;84(2):146-8.

10) Itoh K, Nishimura K, Togashi K, Fujisawa I, Sagoh T, Minami S, et al. [MR imaging of cavernous hemangioma of the face and neck]. Rinsho Hoshasen 1986;31(13):1497-502.

11) Aspestrand F, Kolbenstvedt A. Vascular mass lesions and hypervascular tumors in the head and neck. Characteristics at CT, MR imaging and angiography. Acta Radiol 1995;36(2):136-41.

12) Kanzaki S, Nameki H. Standardised method of selecting surgical approaches to benign parapharyngeal space tumours, based on preoperative images. J Laryngol Otol 2008;122(6):628-34.

13) Sarac S, Koybasi S, Kaya S. Transmaxillary excision of a rare cavernous hemangioma of the infratemporal fossa. Ear Nose Throat J 2000;79(6): 448-9, 452.

14) Fernández Ferro M, Fernández Sanromán J, Costas López A, Sandoval Gutiérrez J, López de Sánchez A. Surgical treatment of benign parapharyngeal space tumours. Presentation of two clinical cases and revision of the literature. Med Oral Patol Oral Cir Bucal 2008;13(1): E61-4.

15) Fisch U. Infratemporal fossa approach for glomus tumors of the temporal bone. Ann Otol Rhinol Laryngol 1982;91(5 Pt 1):474-9.

16) Ohue S, Fukushima T, Kumon Y, Ohnishi T, Friedman AH. Preauricular transzygomatic anterior infratemporal fossa approach for tumors in or around infratemporal fossa lesions. Neurosurg Rev 2012. [Epub ahead 
of print]

17) Shi J, Hang C, Pan Y, Liu C, Zhang Z. Cavernous hemangiomas in the cavernous sinus. Neurosurgery 1999;45(6):1308-13; discussion 1313-4. 18) Zhou LF, Mao Y, Chen L. Diagnosis and surgical treatment of cavernous sinus hemangiomas: an experience of 20 cases. Surg Neurol 2003;60(1):31-6; discussion 36-7.
19) Jinhu Y, Jianping D, Xin L, Yuanli Z. Dynamic enhancement features of cavernous sinus cavernous hemangiomas on conventional contrastenhanced MR imaging. AJNR Am J Neuroradiol 2008;29(3):577-81.

20) Lee SY, Lee JH, Hur GY, Kim JH, In KH, Kang KH, et al. Successful removal of a slowly growing mediastinal cavernous haemangioma after vascular embolization. Respirology 2006;11(4):493-5. 